\title{
A view from the bodies corporate: introduction
}

\author{
Some time ago, several of the bodies corporate were approached by the $B D J$ and asked if they would be prepared to field a \\ director to be interviewed for the journal. The only stipulation was that the director should be one of the dentists on the board. \\ The next few issues of the $B D J$ will feature interviews with those dentist-directors of bodies corporate who accepted the \\ invitation. Of those approached, ADP Dental Company Ltd, Boots Dentalcare Ltd, Integrated Dental Holdings Plc, Oasis Dental \\ Care Ltd, Ora Dental Group Ltd, OrthoWorld 2000 Ltd, accepted. Only two declined the opportunity: Dr J. D. Hull \& Associates \\ Ltd and Dencare Management Ltd. The first interview follows this introduction to the series by Fiona Stuart-Wilson.
}

\section{The same but different}

If I was expecting each interview to follow the same track, I was to be disappointed; at least one director expressed to me the view that the interviews might be similar, but the reality was quite different. Although I had a clear idea of what I was going to cover, the content of the interviews varied even more than the venues selected by my interview subjects, which ranged from the corner of a dental surgery to the more orthodox environment of an office, to a smart London hotel. Different directors took different approaches to the interview; some seemed at the time more open than others (even taking the requirement for confidentiality concerning business plans and acquisitions into consideration) and each gave a different emphasis to their role as a director.

My main introduction into each interview was to identify the different director's views on how each saw dentistry changing within the next five years as an introduction to discussing proposed changes to the Dentists Act concerning deregulation of bodies corporate. How the interview progressed after that depended on the response.

The term 'bodies corporate' is used to refer to a particular group of dental organisations which share the same type of legal entity; however, using the term and grouping them together in this way can make one forget how far they differ in philosophy, plans and approach. The different directors' views also differ considerably on many issues; they are all dentists by training with clear opinions on the future of dentistry and what they see as important to the profession, but three that I spoke to were combining their director's duties with practising dentistry at least a few days a month.

\section{The future of dentistry}

The main direction of my interview with each was their impressions of the likely changes in dentistry and their impact. Some common themes emerged, as well as some major differences in their approaches.

In a period of expansion through acquisition, for some of the corporates at least, I was particularly interested in their criteria for acquiring practices. This varied, but one emerged above all others - location. One common complaint also emerged - that of the unrealistic financial expectations of many practices wishing to sell. Their views on some practices may be unpalatable to some; several of the directors were very forthcoming about this in their interviews and I will allow their words to speak for themselves in this matter.

Another strong theme was the shortage of suitably qualified dental personnel. The shortage of dentists affected most corporates, and the future role of PCDs was under active consideration by them all.

Another message which came over loudly was, in the view of more than one of the directors, what is an untenable payment system for associates. It seems that the days of the 50\% arrangement is numbered in their view. Finance, perhaps unsurprisingly, was a subject to the fore in many of my discussions; these people are of course now directors, with board responsibilities and responsibilities to shareholders, as well as dentists, and as such their purview is broader.

Even for those corporates working outside of the NHS system, NHS remuneration was brought up in the discussions, and not by me. It remains for some a thorny subject, and engendered strong views from some. Interestingly no-one brought up the subject of primary care trusts, although some of them may well be interacting with these bodies in the future.

All of the directors identified similar changes in consumerism, and a public more willing to pay for private dentistry, but all did so in a slightly different fashion. Brand image represented an issue of varying importance for them, but quality was a recurring theme to a greater or lesser extent.

\section{Deregulation}

None of the directors I spoke to saw deregulation as any form of threat, and most positively welcomed the proposed changes to the Dentists Act to allow more practices and groups of practices to incorporate. However, nearly all saw consolidation of the corporate market - some more radically than others. Change for all of them was a constant, and something to be embraced, and some gently (and not so gently) attacked the profession as a whole for what they perceived as its apathy towards change; for them, it was change or die.

And for those considering selling their practice, there are some cautionary messages. If you are in the wrong place it will be difficult to attract the attention of a corporate buyer, and in the absence of a corporate purchaser, there may be far fewer dentists coming through who wish to purchase practices. A gloomy outlook? Not necessarily.

What I hope will emerge from this series is a clearer understanding of some of the business drivers of each of the corporates interviewed, and some insights into the future of the delivery of dentistry in the short to medium-term which their forecasting offers. Time alone will tell how accurate they are. Whether you agree or disagree with their views, I hope that this series will stimulate further debate and forecasting on the part of individual practitioners. 